\title{
NOVOS PACTOS SOCIAIS PARA A PROMOÇÃO DA IGUALDADE NO CONTEXTO LATINO-AMERICANO: AS POLÍTICAS PÚBLICAS NO COMBATE AS INJUSTIÇAS SOCIAIS NA REGIÃO
}

\section{Anna Paula Bagetti Zeifert*}

\section{Resumo}

$\mathrm{O}$ artigo analisa a realidade latino-americana, considerando as injustiças sociais presentes nessa região, de maneira a traçar um possível caminho para um novo pacto social que possibilite pensar políticas públicas eficientes. Nesse contexto, é fundamental estabelecer uma relação entre desigualdade, pobreza e desenvolvimento, considerando que as privações podem produzir redução das capacidades dos indivíduos e a (in)efetividade das políticas públicas para promoção dos direitos sociais. Para seu desenvolvimento o estudo dialoga com a abordagem das capacidades do economista Amartya Sen e com o fenômeno da aporofobia da filósofa Adela Cortina.

Palavras-chave: Aporofobia; Capacidades; Igualdade; Injustiças Sociais; Políticas Públicas

\section{NEW SOCIAL PACTS TO PROMOTE EQUALITY IN THE LATIN AMERICAN CONTEXT: PUBLIC POLICIES IN THE FIGHT AGAINST SOCIAL INJUSTICES IN THE REGION}

\begin{abstract}
The article analyzes the Latin American reality, considering the social injustices present in this region, in order to outline a possible path for a new social pact that makes it possible to think about efficient public policies. In this context, it is essential to establish a relationship between inequality, poverty and development, considering that deprivations can produce a reduction in the capacities of individuals and the (in)effectiveness of public policies to promote social rights. For its development the study dialogues with the approach of the economist Amartya Sen's capacities and with the phenomenon of aporophobia of the philosopher Adela Cortina.
\end{abstract}

Keywords: Aporophobia; Capabilities; Equality; Social injustices; Public policy

\section{INTRODUÇÃO}

\footnotetext{
* Pós-doutora pela Escola de Altos Estudos - Desigualdades Globais e Justiça Social: Diálogos sul e norte, do Colégio Latino-Americano de Estudos Mundiais, programa da Faculdade Latino-Americana de Ciências Sociais (FLACSO Brasil) e UNB (Capes PrInt). Doutora em Filosofia (PUCRS). Professora do Programa de PósGraduação em Direito - Mestrado e Doutorado em Direitos Humanos - e do Curso de Graduação em Direito da UNIJUI. Integrante do Grupo de Pesquisa Direitos Humanos, Justiça Social e Sustentabilidade (CNPq). Email: anna.paula@unijui.edu.br
} 
A América Latina enfrenta um cenário de incertezas, desigualdade e aumento da pobreza, e isso traduz-se em economias fragilizadas que exigem transformações profundas e urgentes. Avançar em um caminho de maior igualdade não é apenas um imperativo ético, mas condição necessária. Todavia, a brecha social que distancia cada dia mais ricos e pobres e aumenta o poder econômico na mão de alguns poucos, corre o risco de ser ainda mais intensa devido à crise pandêmica mundial. Conforme dados apresentados pela própria ONU (2020), “a expectativa de perda de renda ultrapassa os 220 bilhões de dólares nos países em desenvolvimento. Com cerca de $55 \%$ de toda a população global sem acesso a proteção social [...]”, diante da crise sanitária e humanitária.

No documento denominado Panorama Social da América Latina, organizado pela Comissão Econômica para a América Latina e Caribe (CEPAL, 2019a), "a distribuição de renda e da riqueza, a evolução e tendências da pobreza na região, a dinâmica do gasto social, a inclusão social e do trabalho da população e a autonomia econômica das mulheres [...]", são norteadores para que tenhamos sociedades mais justas e igualitárias. Porém, os estudos demonstram que houve um incremento no número de pessoas pobres na região, assim como a pobreza extrema continua sendo um desafio, intensificando os problemas, especialmente aqueles que afetam consideravelmente o bem-estar, a organização das cidades e as condições de vida digna, intimamente relacionados as questões econômicas e de direitos.

As desigualdades, na maioria das vezes, são medidas por meio da expectativa de vida, da taxa de mortalidade infantil e da incidência de doenças. Esse tipo grave de desigualdade relaciona-se com as desigualdades de classe, isto é, com as menores condições de acesso a bens e recurso e, consequentemente, à saúde, tendo em vista que, em muitos países, as populações marginalizadas ou vulneráveis possuem menor acesso e qualidade de atendimento nessa área. Com isso, são postas em evidência as graves desigualdades sociais, econômicas e políticas que estão sedimentadas historicamente na estrutura dos países latino-americanos.

A abordagem das capacidades proposta pelo economista Amartya Sen (2011), conduz a refletir sobre tais problemas e coloca o indivíduo como centro dessas discussões. Da mesma forma, a filósofa espanhola Adela Cortina (2017), a partir do fenômeno da aporofobia, faz um diagnóstico partindo do campo da filosofia para a realidade social, e considera que a sociedade e a humanidade contém em sua própria história um acervo denso e multifacetado de vulnerabilidades. 
Nesse sentido, a investigação que ora se apresenta, orienta-se pelo método hipotéticodedutivo centrado na pesquisa exploratória, tendo por objetivo apresentar uma análise da realidade latino-americana, considerando as injustiças sociais presentes nessa região, de maneira a traçar um possível caminho para um novo pacto social que possibilite pensar políticas públicas eficientes.

\section{PENSAR AS CAPACIDADES É PENSAR NA VIDA QUE SE DESEJA VIVER}

Amartya Sen (2011), economista indiano, propõe pensar a justiça a partir $d a$ abordagem das capacidades, tratando de problemas reais que envolvem a justiça, especialmente a justiça social. Considera fundamental que a justiça seja pensada na sociedade que efetivamente existe e para as pessoas que nela vivem. Acredita que atentar para a vida humana possibilita encontrar a liberdade como um elemento significativo para a satisfação do bem-estar, pois permite ao indivíduo escolher o que considera de valor para sua vida. Portanto, o ser humano possui capacidade de escolher, e essa capacidade de escolha e decisão é possibilitada pela liberdade.

A liberdade é o elemento que possibilita às pessoas a chance real de fazerem o que valorizam para suas vidas, elemento que necessita ser garantido para todos os indivíduos de uma sociedade. Deste modo, o autor faz um apontamento sobre a liberdade que diz respeito à importância de compreender a necessidade de um indivíduo possuir liberdade para escolher um estilo dentro dos diferentes modos de vida. Isto é, a capacidade que uma pessoa possui para escolher a vida que deseja levar. (SEN, 2011)

Assim, conforme entende Sen (2010, p. 29), "Expandir as liberdades que temos razão para valorizar não só torna nossa vida mais rica e mais desimpedida, mas também permite que sejamos seres mais completos, pondo em prática nossas volições [...]”, o que possibilita uma interação maior do indivíduo com mundo em que vive, seja compartilhando experiências ou servindo como influenciador.

Esses apontamentos são importantes para pensar no tipo de vida que um ser humano pode levar com dignidade, pois a possibilidade de realizar escolhas quanto à própria vida é uma questão de dignidade. Na abordagem das capacidades, portanto, o foco é a liberdade que uma pessoa possui para fazer as coisas que tem razão para valorizar. Assim, Sen (2010) 
apresenta um conjunto de liberdades instrumentais que impactam no desenvolvimento, quais sejam: a) liberdades políticas, 2) facilidades econômicas, 3) oportunidades sociais, 4) garantias de transparência e 5) segurança protetora.

\begin{abstract}
As liberdades não são apenas os fins primordiais do desenvolvimento, mas também os meios principais. Além do reconhecer, fundamentalmente, a importância avaliatória da liberdade, precisamos entender a notável relação empírica que vincula, umas às outras, liberdades diferentes. Liberdades políticas (na forma de liberdade de expressão e eleições livres) ajudam a promover a segurança econômica. Oportunidades sociais (na forma de serviços de educação e saúde) facilitam a participação econômica. Facilidades econômicas (na forma de oportunidades de participação no comércio e na produção) podem ajudar a gerar abundância individual, além de recursos públicos para os serviços sociais. Liberdades de diferentes tipos podem fortalecer umas às outras. (SEN. 2010, p. 25-26)
\end{abstract}

Percebe-se, porém, que existe uma desigualdade quanto às capacidades, pois há indivíduos com maior ou menor vantagem ou maior ou menor oportunidade real para realizar as coisas que valoriza. ${ }^{1}$ Sen $(2011$, p. 11) destaca que o objetivo de sua teoria da justiça "é esclarecer como podemos proceder para enfrentar questões sobre a melhorias da justiça e a remoção da injustiça, em vez de oferecer soluções para questões sobre a natureza da justiça perfeita."

Refere o autor, que as políticas públicas que visam a melhoria das capacidades humanas e das liberdades substantivas podem contribuir para um bom resultado por meio da efetivação das liberdades instrumentais distintas, mas inter-relacionadas. Para o referido autor, a "importância intrínseca da liberdade humana em geral, como objetivo supremo do desenvolvimento, é acentuadamente suplementada pela eficácia instrumental de liberdades específicas na promoção de liberdades de outros tipos.” (SEN, 2010, p. 10)

Mas como pensar e propor tais movimentos em favor da liberdade considerando a realidade social latino-americana? Como gerar capacidades em uma população marcada por um histórico de exploração e de um presente com inúmeros problemas sociais, políticos e econômicos?

\footnotetext{
${ }^{1}$ "Certos fatores geográficos, biológicos e sociais multiplicam ou reduzem o impacto exercido pelos rendimentos sobre cada indivíduo. Entre os mais desfavorecidos faltam em geral determinados elementos, como instrução, acesso à terra, saúde e longevidade, justiça, apoio familiar e comunitário, crédito e outros recursos produtivos, voz ativa nas instituições e acesso a oportunidades." (SEN, 2020)
} 
O cenário de incertezas, desigualdade e aumento da pobreza, que ronda a América Latina, e se traduz em economias fragilizadas e indivíduos vulneráveis, requer uma atenção urgente, que desafia qualquer gestor a implementar transformações profundas. Nesse contexto, avançar em um caminho de maior igualdade não é apenas um imperativo ético, mas condição necessária.

La igualdad se refiere a igualdad de medios, de oportunidades, de capacidades y de reconocimiento (CEPAL, 2014). La igualdad de medios se traduce en una distribución más justa del ingreso y la riqueza, y una mayor participación de la masa salarial en el producto; la de oportunidades, en la ausencia de discriminación de cualquier tipo en el acceso a posiciones sociales, económicas o políticas. La igualdad en materia de acceso a capacidades hace referencia a habilidades, conocimientos y destrezas que los individuos logran adquirir y que les permiten emprender proyectos de vida que estiman valiosos. Implica igualdad en los ámbitos de la educación de calidad, la salud, el acceso al mundo digital, la nutrición y las condiciones de vida, reflejadas en un menor hacinamiento y un mayor acceso a bienes duraderos. Por otro lado, la igualdad como reconocimiento recíproco se expresa en la participación de distintos actores en el cuidado, el trabajo y el poder, en la distribución de costos y beneficios entre las generaciones presentes y las futuras, y en la visibilidad y afirmación de identidades colectivas. Entendida como igualdad relacional, hace referencia a cómo las personas perciben el orden colectivo en que viven en términos de igualdad y desigualdad, así como a diversos campos de intercambio social, como la convivencia urbana o en las escuelas. En este sentido, según se verá más adelante, la cultura del privilegio opera como un obstáculo a la igualdad en todas sus dimensiones (CEPAL, 2019a).

Assim sendo, reduzir a pobreza extrema continua sendo um desafio para os países latino-americanos e isso requer mudanças sociais, políticas e econômicas. Muito "embora a região tenha registrado importantes avanços entre a década passada e meados da década presente, $[\ldots]$ ocorreram retrocessos [...] no que se refere à pobreza extrema." Devido a desaceleração econômica da região há a necessidade "[...] de desenvolver e fortalecer as políticas públicas de proteção social [...] abrangendo medidas de inclusão social e laboral, e políticas redistributivas em matéria de renda" (CEPAL, 2019b).

O quadro abaixo apresenta dados relativos a pobreza e a extrema pobreza que afetam os países na América Latina e a tendência até o final do ano 2020. 
Cuadro 7 | América Latina: pobreza y extrema pobreza en un escenario de caída del PIB del 5,3\% y de aumento del desempleo en 3,4 puntos porcentuales en 2020

(En millones de personas y porcentajes)

\begin{tabular}{lrcc}
\hline Año & $\mathbf{2 0 1 8}$ & $\mathbf{2 0 1 9}$ & $\mathbf{2 0 2 0 ^ { \mathbf { a } }}$ \\
\hline Población & 607,7 & 613,5 & 619,2 \\
\hline Pobreza & & & \\
\hline América Latina (18 paises) & 180,6 & 186,0 & 214,7 \\
\hline Tasa & $29,7 \%$ & $30,3 \%$ & $\mathbf{3 4 , 7 \%}$ \\
\hline Pobreza extrema & & & \\
\hline América Latina (18 paises) & 62,5 & 67,5 & $\mathbf{8 3 , 4}$ \\
\hline Tasa & $10,3 \%$ & $11,0 \%$ & $\mathbf{1 3 , 5 \%}$ \\
\hline
\end{tabular}

Fuente: Comisión Económica para América Latina y el Caribe (CEPAL).

a Estas estimaciones son preliminares y no toman en consideración el impacto diversificado entre los sectores productivos y el empleo generado en cada uno de ellos.

Para tanto, necessário e urgente intensificar os esforços para que medidas mais eficazes sejam implementadas no sentido de proteger os indivíduos, estruturando e intensificando “[...] sistemas de proteção social integrais e efetivos, que fortaleçam a capacidade de contar com os recursos necessários para uma vida digna para o conjunto da população" (CEPAL, 2019b); caminho para a construção de sociedades justas e inclusivas.

Frente ao exposto, cabe destacar que a teoria proposta por Sen (2010), considera fundamental a ideia de colocar as pessoas em primeiro lugar nas discussões sobre o desenvolvimento. Afirma que só por meio da liberdade será possível construir uma sociedade realmente justa que tem como fundamento o respeito aos valores que cada ser humano acredita ser importante para viver dignamente.

Trabalhando nessa perspectiva, o autor propôs em 1990, em parceria com o paquistanês Mahbub ul Haq, o Índice de Desenvolvimento Humano (IDH), programa produzido pelas Nações Unidas para o Desenvolvimento (Pnud) que trata sobre o avanço das sociedades com base em três componentes: expectativa de vida, educação e renda. Uma nova maneira de medir o desenvolvimento dos países, considerando não apenas os fatores econômicos, mas também os sociais.

La igualdad está en el centro del desarrollo por dos razones. Primero, porque provee a las políticas de un fundamento último centrado en un enfoque de derechos y una vocación humanista que recoge la herencia más preciada de la modernidad. Segundo, porque la igualdad es también una condición propicia para avanzar hacia un modelo de desarrollo centrado en el cierre de brechas estructurales y en la convergencia hacia mayores niveles de 
productividad, la sostenibilidad económica y ambiental de cara a las futuras generaciones, la difusión de la sociedad del conocimiento y el fortalecimiento de la democracia y la ciudadanía plena. (CEPAL, 2018)

O que se constata da narrativa de Sen (2000, p. 29) é que, dentre suas variadas formas de observar e contemplar a liberdade, ele o faz como elemento acoplado à ideia de capacidade, e o visualiza além do aspecto econômico. Nesse conjunto, as riquezas propiciam meios para se alcançar mais liberdade para levar o tipo de vida que se deseja, mas não benefícios por si só. A concentração de renda e de riqueza constitui um modo restrito de se avaliar a qualidade de vida, diante da sua incapacidade de, per si, propiciar uma boa existência, bem como pelo fato de que existem outras influências que se projetam nos mais variados aspectos da vida humana. Por esta mesma razão que "o crescimento econômico não pode sensatamente ser considerado um fim em si mesmo. O desenvolvimento tem de estar relacionado sobretudo com a melhora da vida que levamos e das liberdades que desfrutamos."

De mais a mais, Sen (2000, p. 18) alerta para os obstáculos que se apresentam neste contexto, os quais devem ser removidos, a fim de que o desenvolvimento seja alcançado. São as principais fontes de privação de liberdade, ou seja, circunstâncias que promovem outras limitações, por se tratarem de "fontes da privação". O autor elucida que consistem em: "pobreza e tirania, carência de oportunidades econômicas e destituição social sistemática, negligência dos serviços públicos e intolerância ou interferência excessiva de Estados repressivos." 2

O economista indiano também observa como determinados grupos são mais afetados nas regiões em que vivem, citando as disparidades no acesso e gozo de direitos entre pessoas negras e brancas nos EUA. Isto é, as privações que afetam igualmente países considerados como ricos diante de seus obstáculos internos. Assimilando sua perspicácia com a realidade do contexto latino-americano, surge um rico debate para as modalidades de privação no que se tem por pobreza multidimensional e discriminação interseccional, correspondentes a

\footnotetext{
${ }^{2}$ Segundo Sen (2020)," a pobreza é um mundo complexo e a descoberta de todas as suas dimensões exige uma análise clara. 'Nós, seres humanos, somos fundamentalmente diversos', explicou o professor recentemente durante encontro da Rede de Redução da Pobreza, iniciativa do Banco Interamericano de Desenvolvimento. 'Não se pode estabelecer uma linha de pobreza e aplicá-la rigidamente a todos da mesma forma, sem levar em conta as características e circunstâncias pessoais'.”
} 
vulnerabilidades sistemáticas, as quais afetam com maior vigor aqueles que, além dos fatores econômico e social, são discriminados e prejudicados pela etnia, cor da pele e pelo gênero ${ }^{3}$.

Desigualdades sociais é a forma mais apropriada para tratar do tema, tendo em vista que assumem diversas formas e possuem diferentes mecanismos e instrumentos. Fernando Luís Machado (2015) fala de multidimensionalidade das desigualdades sociais, partindo da ideia de que as desigualdades podem se classificar em três grandes grupos: desigualdades de classe, desigualdades étnico-raciais e desigualdades de gênero. Além disso, o autor também adota uma outra classificação, de modo que existem desigualdades vitais, existenciais e de recursos. É importante compreender essas duas classificações para melhor entender a dinâmica das desigualdades e como elas são, na maioria das vezes, interligadas e interdependentes.

Desigualdades vitais são "desigualdades perante a vida e a morte, decorrentes de diferentes graus de exposição a riscos fatais. São desigualdades que remetem para o estado de saúde das populações e grupos sociais" (MACHADO, 2015, p. 301). Na contemporaneidade, são as desigualdades medidas através da expectativa de vida, da taxa de mortalidade infantil e da incidência de doenças. Esse tipo grave de desigualdade se relaciona com as desigualdades de classe, isto é, com as menores condições de acesso à bens e recurso e, consequentemente, à saúde, assim como se relaciona com desigualdades étnico-raciais e de gênero, tendo em vista que em muitos países as populações marginalizadas ou vulneráveis possuem menor acesso e qualidade de atendimento na área da saúde.

Existenciais são as desigualdades que remetem ao "reconhecimento de cada ser humano enquanto pessoa" (MACHADO, 2015, p. 302), isto é, da oportunidade e possibilidade de cada indivíduo realizar livremente seus projetos de vida e de acessar direitos. Portanto, as desigualdades existências se expressam através da "insignificância" de determinados grupos e populações, como ocorreu com a escravidão dos povos indígenas e afrodescendentes e com o patriarcado. Esses são apenas alguns dos exemplos de

\footnotetext{
3 "Há disparidades sistemáticas entre o nível de liberdade de que desfruta o homem e a mulher em diferentes sociedades. Além da disparidade no nível dos rendimentos ou recursos, há diferenças em outras esferas, como a divisão das tarefas no lar, o nível de instrução recebida ou o nível de liberdade de que desfrutam os vários membros de uma mesma família. A forma como um indivíduo deve apresentar-se para ser aceito em sociedade a roupa que veste, a aparência que tem - limita e condiciona suas opções econômicas, fenômeno que qualifica de vergonha social." (SEN, 2020)
} 
desigualdades existências da história humana, muitos outros grupos e povos sofreram e sofrem em decorrência disso, pois se trata do tipo mais comum e frequente de desigualdade.

As categorias sociais estão diretamente relacionadas com as desigualdades sociais, especialmente as desigualdades de recursos. As desigualdades sociais são "diferenças sistemáticas e persistentes de acesso a bens, recursos e oportunidades, geradas independentemente dos talentos, capacidades e desempenhos individuais." Falar de cristalização das desigualdades, sejam elas vitais, existenciais ou de recursos, significa dizer que as linhas que separam as posições de vantagem e de desvantagem social se mantêm no tempo e que as pessoas, as famílias, os grupos e as populações inteiras que estão nessas posições tendem também a ser as mesmas. É assim que se formam as categorias sociais que ganham uma existência própria e se tornam socialmente visíveis e designáveis (MACHADO, 2015, p. 303).

As categorias podem transformar-se em comunidades fortemente sedimentas, com sentimento de pertencimento compartilhado entre os indivíduos e pode, além disso, construir uma imagem própria, interna e externa, em relação ao restante da sociedade. Como aponta Machado (2015), grande parte dessas categorias derivam de minorias étnico-raciais, mas podem surgir de classes sociais ou de categorias de pessoas. Nessa dinâmica, o sentimento de pertencimento condiciona o destino dos indivíduos membros dessas comunidades.

A renda não é o único meio para geração de capacidades. Do mesmo modo, sua ausência não constitui o excepcional fator a privar os sujeitos de suas capacidades. Há outras influências que são exercidas, como as necessidades particulares de uma pessoa e as condições sociais do espaço em que vive, por exemplo a ideia de fome e subnutrição: se determinada pessoa tem acesso a uma remuneração adequada e dentro da expectativa de seu país, mesmo que tenha condições de adquirir alimentos para suprir suas necessidades básicas, é possível que tais insumos não sejam produzidos de modo adequado, orgânico e nutritivo. É possível também que, em sendo portadora de doenças parasitárias, ainda que a primeira assertiva não ocorresse, esteja incapacitada de absorver os nutrientes constantes dos alimentos que consome. Portanto, do exemplo mencionado tem-se que, inobstante tenha acesso à renda, há privação da capacidade e da liberdade de saúde e de vida boa do agente em questão.

Nesse contexto, o autor indiano demonstra a pertinência de pensar políticas de inclusão para os indivíduos de maneira a promover a liberdade e a dignidade, uma forma de diminuir o impacto das desigualdades de oportunidades, ou seja, a ideia de que uma sociedade 
justa precisa combater esse problema, pois as desigualdades existenciais refletem na qualidade de vida dos sujeitos.

\section{O SISTEMA EXCLUDENTE E O FENÔMENO DA APOROFOBIA}

A aporofobia é entendida como rejeição, aversão, medo e desprezo pelo pobre e pelo desamparado, ou daquele que não podem colaborar com à sociedade, na lógica de troca do sistema contratualista. Historicamente as sociedades são regidas pelo princípio do intercâmbio, que é baseado na cooperação, no entanto, os pobres são aqueles que não conseguem participar do jogo, tornando-se, por consequência, indesejáveis. Diante disse, Cortina (2017, p. 6), entende que o pobre é excluído “de un mundo construido sobre el contrato político, económico o social, de ese mundo del dar y el recibir, en el que sólo pueden entrar los que parecen tener algo interesante que devolver como retorno"

Combater a desigualdade e a pobreza requer medidas e propostas de acordo com as mudanças políticas, econômicas e sociais que acontecem com o passar do tempo. Na América Latina a desigualdade é uma característica histórica, assim como o alto número de comunidades pobres e sem condições dignas para viver, porém, ainda, uma pequena parcela da população detém o controle e o poder da riqueza.

O Brasil, entre os demais países latino-americanos, possui uma das sociedades mais desiguais e individualistas de todo o mundo, ou seja, a população pobre carece de serviços e bens básicos para levar uma vida com dignidade, sendo colocada em uma situação de vulnerabilidade e risco, tanto no campo econômico, quanto no social e no político.

Nesse contexto, é possível constatar a presença massiva da racionalidade aporofóbica. A aporofobia é um atentado diário, quase invisível, contra a dignidade e o bem-estar das pessoa. Em razão de que o ser humano é um ser de necessidades, mas também é capaz de dar, e disso nasce, em essência, o Estado, há a necessidade da proteção de acordo com os deveres e responsabilidades de cada indivíduo. Os mais necessitados carecem da proteção do poder público, mas também de ações concretas capazes de assegurar a subsistência, isto é, de políticas públicas para atender os direitos básicos, tolhidos pelo sistema econômico e pela exclusão de que são protagonistas (CORTINA, 2017).

No entender da autora, os sujeitos participam da vida em sociedade, usufruindo do intercâmbio social, se beneficiando dessa participação. No entanto, não podem devolvê-lo no 
sentido econômico, tornando-se uma espécie de fardo na perspectiva daqueles que os rechaçam.

\begin{abstract}
Y sucede que, al comprobar que el juego de dar y recibir resulta beneficioso para el grupo y para los individuos que lo componen, este juego ha ido cristalizando en normas de reciprocidad indirecta que forman el esqueleto sobre el que se sustenta la encarnadura de las sociedades contractualistas en las que vivimos, regidas por el Principio del Intercambio. Cualquier actuación espera um retorno, la reciprocación es la base de la cooperación; pero ese retorno no siempre tiene que proceder del beneficiario, sino que bien puede venir de otros. (CORTINA, 2017, 53)
\end{abstract}

Para Cortina (2017, p. 7), o compromisso de assegurar a vida minimamente digna dos vulneráveis é eliminada na sociedade aporófoba; por vezes de forma expressa, em outras, pela omissão. Assim é que "los pobres parecen quebrar este juego del toma y daca, porque nuestra mente calculadora percibe que no van a traer más que problemas a cambio y por eso prospera la tendencia a excluirlos."

Assim, é primordial pensar uma democracia baseada nos valores de liberdade e igualdade, capaz de distribuir justamente os bens. Uma economia fundada em uma ética, com a meta de criar riqueza com equidade, erradicando a pobreza e reduzindo as desigualdades, de maneira a fomentar a cidadania econômica, sendo os cidadãos protagonistas das decisões sobre o desenvolvimento produtivo.

padece falta de libertad, imposibilidad de llevar adelante los planes de vida que tiene razones para valorar, carencia de las capacidades básicas necesarias para tomar las riendas de su vida. Lo cual tiene para quien la sufre consecuencias tan indeseables como no poder ser agente de su vida, sino sólo un sujeto paciente de la lotería natural o social que le toque en suerte, y no poder perseguir la felicidad por el camino que desearía elegir. (CORTINA, 2017, p. 65)

Para tanto, observa-se que nas sociedades contemporâneas, há um afastamento entre o nível de consciência moral das instituições e declarações para o nível das pessoas e da sociedade. Enquanto o Estado e as instituições são legitimados pela defesa dos direitos humanos, a sociedade e seus cidadãos, que também integram as instituições do Estado, não efetivam ou concordam com as ideias referentes à luta pelos direitos humanos.

Ao longo da história, observa-se que as sociedades ocidentais passaram por grandes progressos no que tange à consciência moral, considerando a abolição da escravidão, a luta 
contra a misoginia, o racismo, a homofobia e, atualmente, contra a xenofobia. Analisa Cortina (2017, p. 43), que as sociedades buscam, constantemente, uma maior maturidade moral sobre o justo e sobre a humanidade, porém existe uma longa distância entre aquilo que é proposto e o que efetivamente se concretiza. Todos os documentos que pensam e pensaram promover formas justas de inclusão "en todos ellos, erradicar el hambre, acabar con la pobreza extrema y la desigualdad injusta en sus diversas formas es un objetivo declarado, que forma parte de la moral pensada, escrita, declarada."

Para a autora em análise, a aporofobia possui um alcance universal, o que significa dizer que, em certa medida, todos os seres humanos são aporófobos, pois faz parte das raízes cerebrais e sociais da humanidade. Isto é, a biologia humana foi evoluindo em prol da sobrevivência, de modo que o indivíduo é programado geneticamente para pensar em seu próprio interesse e nas suas necessidades. Apesar disso, os seres humanos praticam uma simpatia seletiva com seu grupo e sua família. No entanto isso não se manifesta quanto aos estrangeiros, estranhos, inconvenientes.

Entretanto, Cortina (2017) argumenta que o ser humano desenvolve uma racionalidade empenhada na cooperação em prol de máximo benefício, sendo o indivíduo um maximizador de sua ganância. Por isso, adota-se uma racionalidade de reciprocidade, do indivíduo capaz de dar e receber, de cooperar movido racionalmente, mas também pelas emoções e sentimentos.

Por um lado, o ser humano está biologicamente preparado para o egoísmo, mas, por outro, ele possui uma tendência à cooperação. Da mesma maneira, apesar e por causa de condições naturais, o indivíduo opta pela construção do Estado de Direito, devido a sua sensibilidade moral, com o desejo de que sejam protegidos por leis e com a liberdade de decidir por seus futuros

A autora espanhola, percebe que há um princípio adaptativo tendente ao cérebro contratualista, que não leva à busca pelo bem da maior número de pessoas, e sim de um pacto de ajuda mútua, cooperação, em que os menos avantajados não fazem parte. Assim também, se o cérebro humano é dissociativo, não é surpreendente que a sociedade evite e rejeite as pessoas que podem ser perturbadoras e que não ofereçam benefícios, ocasionando graves exclusões sociais. Além disso, "la sociedad contractualista y cooperativa del intercambio se excluye al radicalmente extraño, al que no entra en el juego del intercambio, porque no parece que pueda ofrecer ningún beneficio como retorno. Ése es el pobre en cada ámbito de la vida social" (CORTINA, 2017, p. 54). 
Nesse contexto, o pobre é aquele que está fora da possibilidade de devolver algo em um mundo baseado em dar e receber. Por isso, parece perder capacidade adaptativa biológica e social, porque são os "bem situados" que podem ajudar na sobrevivência social e a prosperar. Esses "sem poderes" podem ser os pobres, os deficientes mentais, os indivíduos “descartáveis", isto é, em cada esfera da sociedade, são aqueles que não podem devolver os bens e investimentos que na sociedade são trocados, "que pueden ser favores, puestos de trabajo, plazas, dinero, votos, apoyo para ganar unas elecciones, honores y prebendas que satisfacen la vanidad" (CORTINA, 2017, p. 54).

\begin{abstract}
Éste es el caldo de cultivo, biológico y social, de la aporofobia, de la aversión hacia los áporoi, hacia los que no tienen nada bueno que ofrecer a cambio. Y no sólo si quedan lejos, sino todavía más si están cerca y pueden causar problemas, si pertenecen a la propia familia y se les trata como a una vergüenza que hay que ocultar. (CORTINA, 2017, p. 54).
\end{abstract}

O jogo da reciprocidade consiste em dar com o poder de receber, seja da pessoa a quem se dá algo, seja receber algo de outra pessoa autorizada à troca. Essa é a base das sociedades contratualistas que, por mais que sejam superiores do que o egoísmo, excluem os pobres porque estão submetidas ao princípio da troca, segundo o qual "a quien más tiene más se le dará, y a quien tiene poco hasta lo poco que tiene se le quitará" (CORTINA, 2017, p. 86).

O que fica evidente, diante de tais explicações, é que os pobres provocam um sentimento de desprezo, tendo em mente a percepção dos mais abonados: de que aqueles apenas trazem problemas e que impedem seus ideais de desenvolvimento e evolução. Esse sentimento se manifesta no momento em que determinados grupos se entendem como melhores e superiores, munidos de um desejo constante deles se livrar, como se não fossem sujeitos humanos, mas coisas. A rejeição, incorporada evolutivamente pelo cérebro, tem outras razões, como sociais e econômicas, as quais necessitam ser superadas (CORTINA, 2017). A invisibilidade do pobre e dseu desprezo é algo intrínseco a própria vida em sociedade.

A superação de tais questões só será possível a partir do momento em que a compaixão não deve existir somente no jogo de trocar e receber, mas no reconhecimento de que o outro é um igual; um vínculo que existe antes de qualquer contrato social. Para a efetivação dessa transformação em direção aos ideais igualitários é necessário contar com a 
educação familiar e escolar, com os meios de comunicação e com o conjunto da vida pública, construindo instituições e organizações que caminhem com o objetivo de construir um mundo mais igualitário e justo. Nesse sentido,

\begin{abstract}
de crear instituciones políticas, educativas y culturales, como las que intentan potenciar una neurodemocracia frente a los delitos y discursos del odio a los pobres, a los mal situados en cada caso. Pero no basta con la política, la educación y la cultura, porque el peso de las instituciones económicas y de la vida económica en su conjunto es extraordinario, tiene una decisiva influencia en la conformación del modo de pensar y de actuar. (CORTINA, 2017, p. 87)
\end{abstract}

Diante de tais considerações, apresentadas pela autora, constata-se que a potencialização de alguns fenômenos tende a acirrar os problemas decorrentes do modelo econômico neoliberal implementado como solução para os problemas estatais. O sistema capitalista neoliberal e seus ideais de autossuficiência e ausência da participação do Estado, tanto nas relações privadas quanto públicas, faz com que parte da sociedade, as minorias e aqueles que estão a margem do sistema, sobrevivam apenas da solidariedade de alguns pequenos grupos. Isso demonstra a ausência do Estado, que se exime da responsabilidade de defesa da vida.

Voltar-se, novamente, para a realidade latino-americana auxilia na percepção dessa problemática vivenciada cotidianamente pela maioria dos indivíduos que habitam essas regiões.

O quadro a seguir, apresenta um panorama do momento e dos efeitos graves decorrentes da pandemia, e como essa situação vai potencializar os problemas que, historicamente, marcam a realidade social e econômica dos povos latinos. (CEPAL, 2020) 


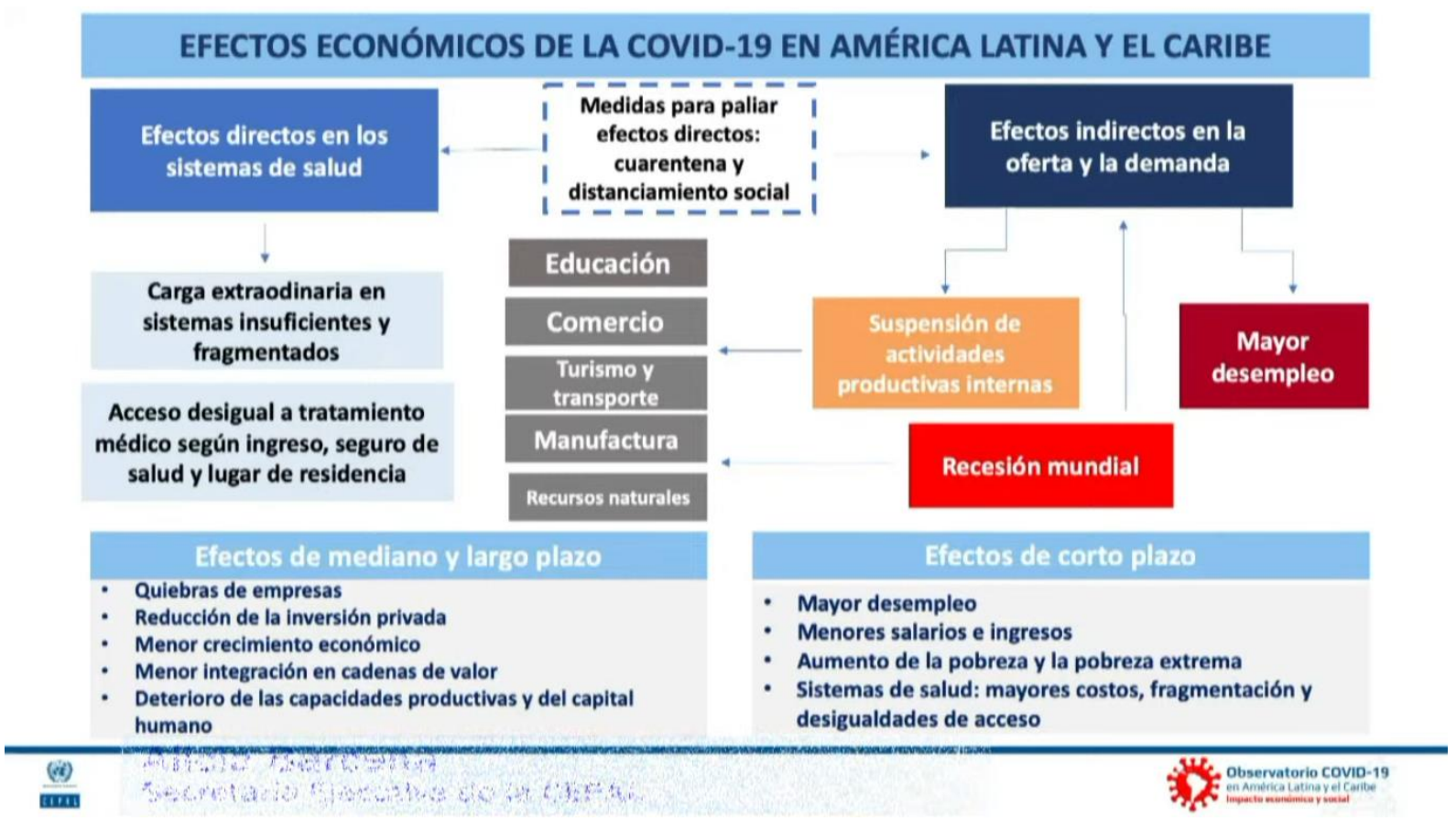

FONTE: CEPAL (2020)

Diante do quadro apresentado, é possível constatar que será fundamental o implemento de políticas tanto no âmbito econômico quanto social para minimizar os efeitos decorrentes da crise de saúde e humanitária que se instala na região, um cenário que exige extrema atenção, visto que a América Latina já se encontra em um contexto de recessão e agravamento dos problemas sociais.

El coronavirus afectará el número de empleos (aumento del desempleo y el subempleo), la calidad del trabajo (reducción de salarios y menor acceso a la protección social) y a los grupos más vulnerables, como los trabajadores en el sector informal. Las estimaciones de la Organización Internacional del Trabajo (OIT, 2020) indican un aumento del desempleo mundial de entre 5,3 millones de personas y 24,7 millones de personas, con una base de 188 millones de personas desocupadas en 2019. En un escenario "medio" el aumento del desempleo sería de 13 millones de personas. La pérdida de ingresos laborales se traducirá en un menor consumo de bienes y servicios, y puede llevar a muchos trabajadores a situaciones de pobreza. La crisis tendrá mayores impactos en los más vulnerables: personas con problemas de salud subyacentes, adultos mayores, jóvenes desempleados, personas subempleadas, mujeres, trabajadores desprotegidos y trabajadores migrantes, con los consiguientes aumentos en la desigualdad. (CEPAL, 2020)

Esse cenário de incertezas e de aumento das vulnerabilidades faz com o rechaço daquele que é inconveniente no espaço comunitário, por questões relacionadas a sua condição 
social e econômica, se sobressalte. O Estado, quando demandado, não dá conta de atender as exigências, agravando o quadro que já é de extrema atenção, reduzindo a capacidade dos indivíduos de atingirem níveis satisfatórios de proteção e participação na vida social.

\section{CONCLUSÃO}

A abordagem das capacidades emerge como uma alternativa para a implementação de políticas voltadas para a garantia da dignidade humana, bem como da justiça no âmbito da sociedade. As políticas públicas dirigidas a melhorar a igualdade de oportunidades são mais capazes de reduzir desigualdades do que políticas de estímulo econômico, isso porque a desigualdade é relevante e interfere nas possibilidades de equidade e justiça social.

Para Sen a noção de que a renda e riqueza poderiam ser capazes de apontar as questões de qualidade de vida e bem-estar, se passasse a considerar as diferenças e desigualdades presentes na sociedade para adequar a quantidade de dinheiro direcionada para as necessidades básicas dos indivíduos.

Nesse sentido, nas teorias sobre a justiça social produzidas na contemporaneidade, é possível observar as discussões em torno do respeito as necessidades humanas fundamentais e a responsabilidade do Estado e da sociedade na efetivação de tais demandas. A abordagem das capacidades emerge como uma alternativa para a implementação de políticas voltadas para a garantia das necessidades humanas fundamentais, bem como na garantir da justiça no âmbito das sociedades.

Pensar as políticas públicas, na contemporaneidade, em especial as políticas de inclusão social, que se coadunem com a realidade de um mundo globalizado, não apenas economicamente, mas também no âmbito social é, antes de tudo, analisar o fenômeno da globalização, o qual não deve ser visto apenas sob o prisma econômico.

Todavia, é certo dizer que é no campo econômico que surgem as manifestações mais perceptíveis da globalização, mas a questão pode ser percebida e estudada em outras esferas da sociedade, pois mudanças importantes ocorreram também nos campos social, cultural e político.

Para tanto, falar em justiça social é sinônimo de um pensamento que remete à ideia de busca e consolidação de direitos, vislumbrando, através da implementação de políticas 
públicas de inclusão, uma possibilidade voltada para a garantia das necessidades humanas básicas, bem como ao acesso igualitário a uma sociedade justa e cooperativa.

A noção de aporofobia, que se traduz pelo desprezo e rechaço ao pobre, ao inconveniente, aquele que não participa da lógica de troca da sociedade contratualista, também emerge como algo a ser considerado no momento que se pensa que tipo de sociedade interessa construir. A responsabilidade de construir políticas públicas capazes e suficientes para atender os anseios da sociedade, reduzindo as desigualdades sociais e a pobreza, emergem como um cenário de alento para muitos cidadãos.

Assim sendo, tanto a liberdade quanto a igualdade são fundamentais para maximizar a eficiência econômica das sociedades, pois possibilita criar um ambiente institucional, político e de esforço que priorize a inovação e a capacitação. Neste contexto, promover a igualdade é intensificar os esforços para que uma sociedade seja considerada inclusiva.

\section{Referências}

CEPAL), La ineficiencia de la desigualdade. Santiago, 2018. Disponível em: https://repositorio.cepal.org/bitstream/handle/11362/43442/6/S1800059_es.pdf. Acesso em: 30 abr. 2020.

CEPAL. La matriz de la desigualdad social en América Latina. Santiago: Nações Unidas, 2016. Disponível em: https://www.cepal.org/sites/default/files/ events/files/matriz_de_la_desigualdad.pdf. Acesso em: 9 abr. 2020.

CEPAL. Anuario Estadístico de América Latina y el Caribe, 2019. Santiago, 2020. Disponivel em: file:///D:/Usuario/Downloads/S1900583_mu.pdf. Acesso em: 30 abr. 2020.

CORTINA, Adela. Aporofobia: el rechazo al pobre. Un desafío para la democracia. Barcelona: Paidós, 2017.

ONU (Organização das Nações Unidas). Entrevista: Entenda a nova linha global de pobreza. ONU News, [s. l.], out. 2015. Disponível em: https://news.un.org/pt/audio/2015/10/1149521. Acesso em: 13 abr. 2020.

MACHADO, Fernando Luís. Desigualdades sociais no mundo atual: teoria e ilustrações empíricas. Mulemba, Revista Angolana de Ciências Sociais, Lisboa, Portugal: Edições Pedago, 2015. Disponível em: https://ciencia.iscte-iul.pt/publications/desigualdades-sociaisno-mundo-atual-teoria-e-ilustracoes-empiricas/27853. Acesso em: 29 mar. 2020.

SEN, Amartya. Desenvolvimento como Liberdade. Tradução de por Laura Teixeira Motta. São Paulo: Companhia das Letras, 2000. 
SEN, Amartya. A ideia de justiça. Tradução de Denise Bottmann e Ricardo Dominelli Mendes. São Paulo: Companhia das Letras, 2011.

SEN, Amartya. Amartya Sen e as mil facetas da pobreza. Banco Interamericano de Desenvolvimento, 2001. Disponível em: https://www.iadb.org/pt/noticias/artigos/2001-0701/amartya-sen-e-as-mil-facetas-da-pobreza\%2C9286.html. Acesso em: 30 abr. 2020.

SEN, Amartya. KLIKSBERG, Bernardo. As pessoas em primeiro lugar: a ética do desenvolvimento e os problemas do mundo globalizado. Tradução de Bernardo Ajzemberg e Carlos Eduardo Lins da Silva. São Paulo: Companhia das Letras, 2010. 